\title{
Caring for parents: a consequentialist approach
}

\author{
William $\operatorname{Sin}^{1}$
}

Published online: 17 October 2015

(C) Springer Science+Business Media Dordrecht 2015

\begin{abstract}
In this paper, I explain the demands of filial obligations from act and rule consequentialism. More specifically, I defend a rule-consequentialist explanation of filial obligations, and identify a few factors in relation to the determination of filial demands; they include the costs of internalization of filial obligations, and the proportions of the young and the old generations in a population pyramid. I believe that in a society with an aging population, we may accept a strong view of filial obligation. Towards the end of the paper, I explain that rule-consequentialism is compatible with certain special views of filial obligations, such as the gratitude theory and the special goods theory; these theories represent ways in which adult children and their parents may obtain special goods from engaging in the relationship.
\end{abstract}

Keywords Consequentialism - Long-term caregiving · Filial obligation - Demandingness - Population - Special goods theory

What would we do when our parents fell ill and became dependent on us on a long-term basis? Certainly, when the unfortunate event broke out, we would rush to help them in the best way we could. But as the matter lingers on, we might become less able to deliver what we initially desired to do. ${ }^{1}$ There is a motivational problem here and also a moral problem, viz. how far morality requires adult children to make sacrifices on behalf of their aging parents.

William Sin

sinwailam@gmail.com

1 Department of International Education and Lifelong Learning, The Hong Kong Institute of Education, 10 Lo Ping Road, Tai Po, New Territories, Hong Kong
The answers to both problems may be dependent on a range of cultural and political factors, including the level of government support to the family caregivers, the cohesion of the neighborhood in a community, and the general expectation in society in regards to the provision of filial care, etc.

In this paper, I will focus on the moral side of the matter. Call it the problem of long-term caregiving: it is very demanding if adult children have to support their aging parents indefinitely. But if they choose to provide less support, or to withdraw it altogether from their parents, this may invite some serious moral reprimand. It has always been a taboo to commit parricide; it may be a vice to give up on caring for parents.

The problem of long-term caregiving concerns more than just a small number of people in the world. The world's population is aging at a rapid pace. The percentage of old people has been estimated to be more than double worldwide over the next half century [United Nations (UN) 2010; United Nations Development Programme (UNDP) 2013]. At present in the United States, most of the elderly are taken care of by friends and family in a domestic context. Eighty percent of them have one or more chronic health problems, such as heart disease, cancer, stroke, arthritis, and dementia, etc. [U.S. Department of Health and Human Services (U.S. DHHS) 2013].

How far should adult children be responsible for supporting their parents' lives? First, one may adopt an Extreme View, arguing that the adult children are under an obligation to bear sacrifices indefinitely. For it seems odd to claim that morality permits adult children to stop

\footnotetext{
${ }^{1}$ Family caregivers often suffer from a number of stress problems. See, for instance, Aneshensel et al. (1993, pp. 54-70), or Day and Alston (1988, pp. 113-119).
} 
assisting their parents. The Extreme View is demanding in nature, and it may be supported by the doctrines of actconsequentialism and Confucianism. ${ }^{2}$ A rival position is the Moderate View, which states that it is morally permissible for adult children to stop supporting their parents even if they have not sacrificed a great deal. ${ }^{3}$ The Moderate View, however, is different from egoism since adult children are required to sacrifice up to a substantial amount before they can stop giving assistance. The Moderate View does not impose an over-demanding burden on adult children. Yet, since it allows them to give up on their parents without bearing great sacrifices, this permission can be problematic. $^{4}$

How should we decide between the two views? And, how should we understand the grounds of filial obligations? There has been a commonplace belief that since filial obligations fall under the scope of imperfect duties, the level of their demands are vague and indeterminable. In this paper, I will show how we may explain the strength of the demands of filial obligations with reference to the doctrines of act and rule-consequentialism. My view is that whereas the prescription of act-consequentialism is objectionable for imposing extreme demands on adult children, the consideration of rule-consequentialism may also give rise to a strong view of filial obligations; but, this prescription can be explained by relatively low internalization costs, and the presence of more old people than young one in a given population.

I believe that, other things being equal, in an aging society, the Extreme View will have more appeal than the Moderate View. It is important to note that the Extreme and the Moderate Views are connected by a continuum, and the two views involve broad categories. Note that the Extreme View itself may involve the strongest possible version as well as the mild version; it is possible to put my view in a moderate manner: the filial obligations of an aging society would, from a rule-consequentialist point of view, fall under a position more to the extreme side than those of a society with many young people. ${ }^{5}$

\footnotetext{
${ }^{2}$ Confucians believe that adult children have strong obligations to reciprocate, and that filial obligations trump other moral concerns. See 13.18 of Analects (Confucius 1979), and 7A35 of Mencius (Mencius 1970). On a moderate interpretation of the Confucian demands, see Ivanhoe (2007, pp. 297-311).

${ }^{3}$ For a description of the basic positions in regards to the limits of sacrifices, see Kagan (1989, p. 1, pp. 6-7).

${ }^{4}$ It is possible to identify a third response, viz. the minimal view. Some writers hold that adult children are not morally responsible for supporting their parents' lives at all, and that filial obligations are by their nature oppressive or parochial. See Simmons (1979, pp. 157-190) and Slote (1979, pp. 319-326).

${ }^{5}$ Despite the fact that there are grey areas, I will prefer not to abandon the distinction between the Extreme and the Moderate Views. I think this distinction makes sense because the two views
}

In the last section of the paper, I will mention special views of filial obligations, such as the friendship theory, the gratitude theory, and the special goods theory. I will explain why the rule-consequentialist view has a stronger explanatory power than that of these theories. In addition, I will argue that despite their apparent differences, the two types of theories are compatible with one another. That is, we may use the contents of the special theories, i.e., the special goods and the gratitude theories, to flesh out the rule-consequentialists' structural claims. As a result, we may see that a consequentialist explanation of filial obligations may not necessarily reduce the moral relation between the adult children and their parents to an instance of general obligations.

\section{Act-consequentialism and the iteration of demands}

Before I explain the demands of act-consequentialism, I shall introduce Joan's case. Joan is a housewife with two teenage children. Her father, Jack, has been a responsible father to her, and was diagnosed with Alzheimer's a few years ago. Since then, Jack has moved into live with Joan and her family. Every day, in addition to the ordinary housework, Joan has to help Jack get dressed, take medicine, clean him and respond to his repeating questions and demands. At the moment, although Joan can manage the basic caregiving work, Jack's condition will become worse, and Joan's own quality of life will be compromised further. ${ }^{6}$ Now, there is a conflict of duties between Joan's role as a good mother and her role as a responsible daughter. But our concern is about the demands of filial morality, and the need for Joan to maintain her personal well-being. Our question is: if Joan desires to live "a life of her own," will morality permit her to do so? ${ }^{7}$

Act-consequentialists claim that agents should do the action which best promotes the overall good. In our case, Joan may be required to bear great sacrifices to give care to Jack insofar as her caregiving actions can promote Jack's well-being in a more effective way than what she can do to other people in the world. May act-consequentialism really

\footnotetext{
Footnote 5 continued signify positions concerning whether it is morally permissible to stop helping (or to provide less assistance to) one's parents after a substantial aggregate sacrifice has been made.

6 See also Sin (2013).

7 I have made large assumptions with regards to the agent's and the patient's situations. Joan may face a different level of filial demands, if, for instance, she has siblings who are willing to share the filial burden of providing care to Jack, or if Jack is wealthy enough to sponsor Joan's life generously.
} 
impose such a requirement on Joan? It may be so, and here are the reasons.

First, generally speaking, adult children have an intimate understanding of what their parents desire and value. So, their helpful actions will address their parents' needs more fairly than the acts of assistance they may provide to strangers. ${ }^{8}$ Second, because of the proximity between the agent and the recipient in the case of long-term caregiving, adult children can deliver their assistance to parents with low transaction costs. Third, many adult children do accept that they have a substantial obligation to care for their parents. This will make it easier for them to perform the helping actions. Under normal circumstances, adult children do not have to alter a great deal of their life plans in order to fulfill the filial requirement. The case will be quite different if we compare it with the great moral demands for affluent people to assist the starving needy in poor countries.

These points are not new. Jackson has argued that the aid agents provide to those who are nearest and dearest to them have a superior probability function in promoting the overall good (Jackson 1991). ${ }^{9}$ Mutual trust and affection will provide good grounds, from the consequentialist perspective, for Joan to continue providing care to Jack. What Jackson has not discussed in his paper is when Joan will be morally allowed to stop or slow down her performance of such acts, or how burdensome this requirement is.

As Joan provides care to Jack, such as feeding him or helping him to take medications, the net sacrifice with regards to each act of assistance seems to be trivial, and the benefits to Jack are great. On this point, not only consequentialism, all plausible moral theories may accept that Joan has the obligation to perform the trivial actions (Singer 1972, p. 235, p. 241; Griffin 1996, p. 82; Unger 1996, p. 7; Scanlon 1998, p. 224). However, the verdicts of consequentialism and those of other moral theories diverge, as adult children have to comply with the demands time and again.

There are two possible responses to the concern about the limits of the demands of easy rescue over time, namely the aggregate view and the iterative view. Supporters of the aggregate view argue that if Joan has been providing care to Jack long enough, and if her aggregate sacrifices have reached a certain substantial amount, she is morally permitted to terminate her assistance to Jack. So, as per the aggregate view, Joan's past sacrifices in regards to this mission is pertinent to the determination of her obligation

\footnotetext{
${ }^{8}$ Despite the positive picture I project with reference to the parentchild relation in general, I am not ignorant of the fact that intergenerational relationships can be less ideal than what we depict here (Lüscher and Hoff 2013, pp. 39-64).

${ }^{9}$ For some classical presentations, see Bentham (1970), and Sidgwick (1907).
}

to Jack now. With the iterative view, since Joan's performance of each of the beneficent actions may not cost her a significant loss, and as great benefits may always be generated from her performance of these actions, act-consequentialism may require Joan to perform the actions indefinitely. ${ }^{10}$

Because of its possible association with the Moderate View, the aggregate view has a stronger appeal than the iterative one. But, the aggregate view also has a worry. It permits adult children to stop providing assistance while they can still help their parents at trivial costs to themselves. This permission is odd because the demand of trivial sacrifices may have an open nature. It seems that people may not "retire" from the obligation to provide easy rescue even if they have done many good actions before.

However, compared to the aggregate view, the iterative view seems to be more counterintuitive since it requires adult children to bear trivial sacrifices without end. Between the worry of demandingness and that of limited mercy, I think we may prefer to live in a world where agents show limited mercy to the needy, than in a world where agents are indefinitely locked up with those in need of their assistance. Here, because of the close alliance between act-consequentialism and the iterative view, if we reject the iterative view for its demandingness, we may reject the act-consequentialist demands of filial obligation, too.

\section{Rule-consequentialism, internalization, and demographic processes}

Rule-consequentialism differs from act-consequentialism in two ways. First, it is a collective theory instead of an individual one: rule-consequentialism does not just ask agents as individuals to promote the overall good; it takes into account the effect of people's collective performance in regards to the promotion of the overall good in the long run. Second, it is an indirect theory. Agents are not expected to promote the overall good directly in their actions; they are expected to promote the good by their accepting (and observing) a certain set of optimal rules (Mulgan 2001, p. 6).

Rule-consequentialism avoids a number of problems which have caused trouble to act-consequentialists. First, as it is the general performance of all people that is collectively coordinated to promote the overall good, rule-

\footnotetext{
${ }^{10}$ It is possible to use the aggregate view to support the Moderate View. But, in principle, the aggregate view is compatible with the claims of the Extreme View, too. A moral theorist may believe that adult children should make great aggregate sacrifices before they are allowed to stop supporting their parents.
} 
consequentialism may distribute a fair share of the burden to all participants in society (Mulgan 2001, p. 54). Second, as an indirect theory, its decision-making procedure is greatly simplified. Agents do not have to estimate the total harm and benefit of their particular actions before they perform them in normal circumstances. Third, rule-consequentialism pays attention to the effects of people's internalization of moral rules. ${ }^{11}$ Very demanding moral rules may be excluded from consideration. Given the nature of human beings, it is costly to get children to accept rules which require them to bear great sacrifices for those who are in need; it will also be difficult to maintain a society in which agents comply regularly with such rules (Hooker 2000, p. 90).

Turning to the case of long-term caregiving, I believe that the doctrines of rule-consequentialism require adult children to follow strong filial obligations in the context of an aging population; in other words, under the current situation of the world, rule-consequentialists may support the Extreme View over the Moderate View. I shall offer two reasons to defend my view. The first is about internalization costs, and the second the demographic structure of society.

In many cases, people's compliance with a set of demanding moral rules may give the needy a great sum of total benefits. But since it is costly to educate the children to accept demanding moral rules, these rules may not be recommended by the rule consequentialists. ${ }^{12}$ For this reason, it is sometimes more cost effective to inculcate in children a set of weaker moral rules for society. Hooker claims that in the case of famine relief, rule-consequentialism may not recommend strong obligations (1990, p. 72; 2000, pp. 170-173).

May we apply the same thought to the subject of filial obligations? There might be reason to support the Moderate View than the Extreme View. If we adopt the Extreme View, each generation of adult children would have to forgo many important goods in order to support the lives of their aging parents. But, the Extreme View is more justifiable than it seems; it is easier to internalize the moral demands to save people's own parents' lives than to internalize the moral demands to save strangers' lives in remote countries. Children are born with strong instincts to protect their parents. The costs of internalizing strong filial

\footnotetext{
11 In Hooker's words: "An act is wrong if it is forbidden by the code of rules whose internalization by the overwhelming majority of everyone everywhere in each new generation has maximum expected value. The calculation of a code's expected value includes all costs of getting the code internalized" (Hooker 2000, p. 32).

12 Hooker (2011): "We are to imagine the children start off with natural (non-moral) inclinations to be very partial towards themselves and a few others. We should also assume that there is a cognitive cost associated with the learning of each rule."
}

obligations among children will be lower than what we might initially expect. ${ }^{13}$

If we accept the Extreme View, does it follow that we must also accept the iterative view over the aggregate view? Not so. It is possible to accept the Extreme View without accepting the iterative view. People may follow a filial rule which requires them to make great life-time aggregate sacrifices. That is, even if agents do not take every opportunity to save victims, this does not mean that they have permanently shut the gate of mercy on mankind (Hooker 2000, pp. 168-169). Of course, it matters how often we may "reopen" the gate of mercy to mankind. I think with reference to the issue of long-term caregiving, the frequency can be set higher than that of saving strangers, as it may involve a relatively low internalization cost. This version of the aggregate view is also less intrusive to people's lives than the iterative one. ${ }^{14}$

There is one more point I shall make regarding the ruleconsequentialist defense of the Extreme View. The existence of the close bond between parents and children is a fixed factor in favor of strong filial rules. There is a variable factor, too: the proportion between the old and the young generations in a given population. In an aging population, the population pyramid displays a kite structure; there is a much higher percentage of old people than that of the young. This phenomenon may come with a combination of long life expectancy and low birth rate (see, for instance, Fig. 1, the projection of Japan's population in 2050). As a result, there will be a great need in society for adult children to provide long-term care to parents, intensifying the pressure for the rule of filial obligations to be set strongly. Under this circumstance, the benefits may outweigh the costs if strong filial rules, instead of moderate ones, are promoted in society.

In fact, there are benefits as society adopts a strong filial rule. Parents may feel a stronger sense of security, and the trust between members of the two generations may be strengthened. Consider a case where a person dies in his early 70s before he needs his children to take care of him, and suppose long ago his children were inculcated with strong filial obligations towards their parents. In this case, the father may not receive the benefit of being cared by his children in his old age, since he dies before that would have

\footnotetext{
${ }^{13}$ Under an aging population, one may be tempted to take a short cut and argue that the younger generation as a whole has a strong collective responsibility to take care of the elderly in general. But, the limit of this point is that it has overlooked the difference of internalization costs between promoting the stringent rules to help everyone who is in need, and promoting the stringent rules to help an agent's own parents.

14 The mixture view is my interpretation. Basically, Hooker (2000, p. 167) himself states that the rule-consequentialists will prefer "the less demanding, aggregative assessment of personal sacrifice, rather than the iterative one."
} 


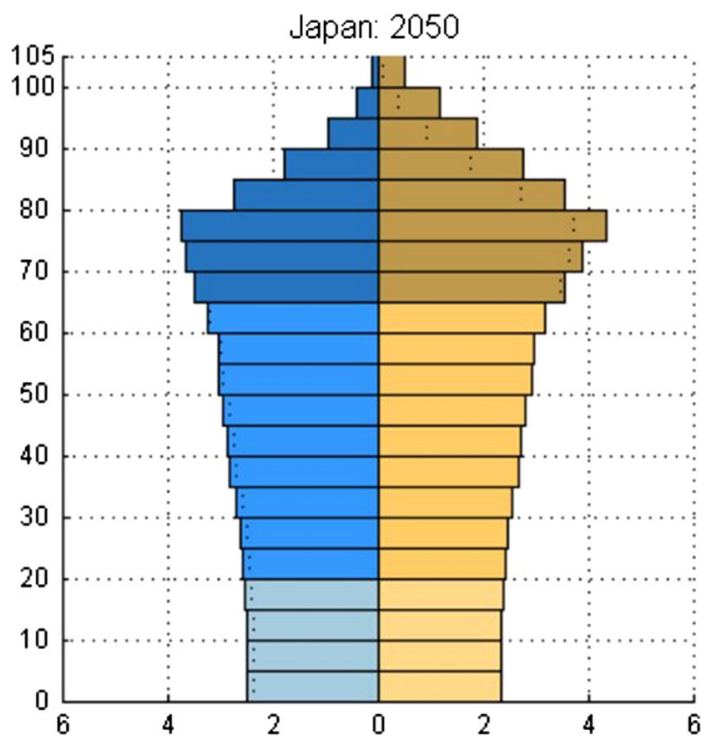

Fig. 1 The projection of Japan's population in 2050 (United Nations 2010)

happened. However, there is the benefit to the father during his $40 \mathrm{~s}, 50 \mathrm{~s}$, and $60 \mathrm{~s}$ of believing that his children will take care of him if he lives long enough to need being taken care of.

With regards to the figure above, in the estimation of the costs and benefits for any model of filial obligations, it is expected that the sacrifices would be borne by each generation of adult children, and the benefits received by the aging parents. There is no reason to consider the young and the old as two distinct groups, whose interests balance against one another. If filial rules are persistently practiced and followed, the majority of people in society will bear the costs and receive the benefits which filial rules bring about. ${ }^{15}$

To illustrate the relevance of demographic development to the determination of filial rules, I shall consider a different population structure. With regards to an expanding pyramid, the percentage of young people would be much higher than that of the old, and the birth rate would be rising, too (see Fig. 2). Against this background, if we promote weak filial obligations in society, the elderly will benefit less than they would have in a society with stringent filial obligations. But, since there are significantly fewer

\footnotetext{
15 Thompson (2009, p. 102): "Peter Laslett and James Fishkin, who criticise the way in which philosophers treat generations as discrete units that succeed each other, suggest that we think of the temporal dimension of a society as being rather like a procession of indefinite length. People are continually joining and leaving the procession (Laslett and Fishkin 1992). They march along, intermingling with others in their vicinity. Laslett and Fishkin point out that the division of these marchers into generations is at best artificial and at worst misleading, and they prefer the term 'processional justice' for what the people in the march through time owe to each other."
}

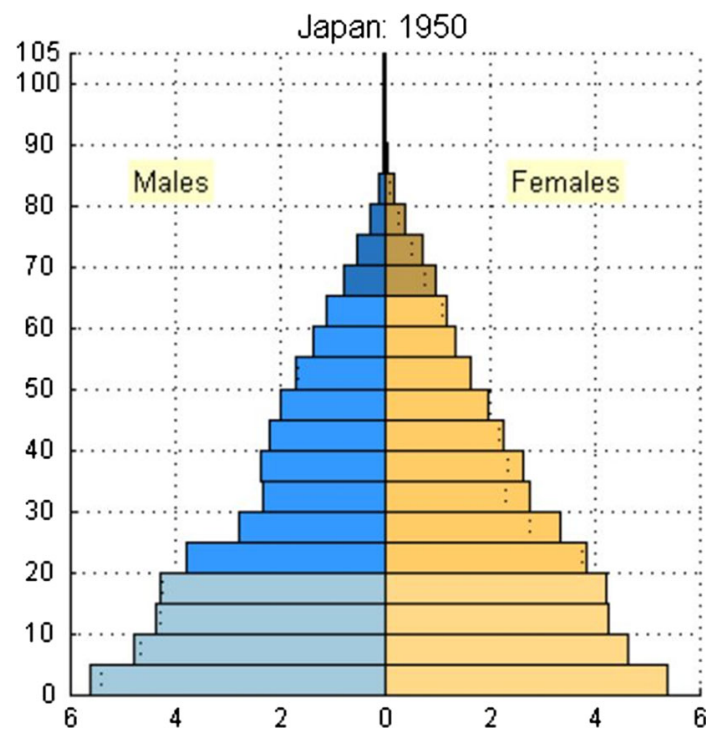

Fig. 2 Japan's population in 1950 (United Nations 2010)

elderly people than young people in this population pyramid, it would be more favorable to promote weak filial rules. The weak rules will give adult children greater freedom, and such rules may be taught and learnt in society without great resistance from human nature. Of course, we should take note of the potentially negative effects generated by the promotion of a relatively ambivalent filial relation between children and parents in this society, as morality permits adult children to give up on their aging parents under a greater number of occasions.

In short, as per rule-consequentialism, it would be worth promoting weak filial obligations in a society with an expanding population. And strong filial obligations would suit a society in which the population is aging. Of course, this argument would only have force if the majority of people form families and have children of their own. If only a small sector of the population chose to have children, or, if a significant number of old people were childless, or were from immigrant families, it would be unclear if the population structure would favor strong filial rules or weak ones.

I shall now address two objections to my argument. I claim that the age structure of a population is a factor which affects how far adult children are obligated to take care of their parents. The first objection is that as the population structure of a society may change over a generation's time, this may make the content of filial obligations change swiftly. If this were the case, the respective conception of moral rules would be impracticable since moral education is not like a tap which can open or close as need be. People of each generation will need to have a clear expectation of what they should teach their offspring in regards to such moral matters. 
In reply to this objection, I have two reminders. First, the demographic development of the world is not the only factor which determines the burden of filial obligations. Apart from demographic considerations, the established way of life in the treatment of elderly, the mode of interaction between members of different generations in a society, etc., will also affect the demands of filial obligations. Second, we should bear in mind that abrupt changes in moral rules and the contents of moral education would be costly. Unless the benefits to society are great enough, it would not be worthwhile to alter the level of demands of an obligation. Taking together, it is clear that not every alteration of a population will trigger a corresponding change in the moral demands of filial obligations.

There is a second objection with regards to the ruleconsequentialist analysis of filial obligations. In my view, the demographic distribution of a society may ceteris paribus determine the level of demands of filial obligations. However, critics of consequentialism may argue that the connection between the two domains, viz., the burden of a moral demand and the features of population structure, is too remote to be worth considering. If elderly people live at a time when they are a minority, it seems to be bad luck for them; their children will have weaker obligations towards them. Alternatively, adult children may ask why the age make-up of the population would change their obligation to their parents, or why this factor would burden them with an obligation to provide care to their parents in their old age.

In response to this objection, I think a global consideration of the nature of obligation will inevitably involve remote as well as intimate factors. For example, whether an agent should help a stranger whose car has broken down can depend on the population density of the region, and even the conditions of the weather where the event takes place (Scanlon 1998, p. 329). The agent may not object to the demands of an obligation simply because the relevant factor is outside the immediate scope of concern of his life.

Of course, from an agent's point of view, the remoteness of a factor in the consequentialist consideration can be worrying, because it is not a suitable source of motivation for him to fulfill his obligations. However, the objective of rule-consequentialist analysis is not to identify the deliberative factors which an agent must adopt to decide how he treats his loved ones. The objective of rule-consequentialist analysis is to identify the set of moral codes worthy for society to adopt and its people to follow in general. Once the rule-consequentialists have identified the best code for society to adopt in the long run, it will be the business of moral education to cultivate people's motivation to comply with the code. ${ }^{16}$

\footnotetext{
16 See also Hooker (2000, p. 141) and Jackson (1991, pp. 467-470).
}

\section{The special views of filial obligations}

This is the final section of the paper. In this section, I will outline four non-consequentialist theories regarding the nature of filial obligations, and will show the merits of the consequentialist approach to filial obligations over the approaches provided by these views. However, towards the end of the section, I will explain the ways in which some of these are compatible with the rule-consequentialist viewpoint. Since there have been an ample amount of discussions in regards to these special views in the literature, viz. debt theory, gratitude theory, and friendship theory, I will not repeat them in this paper. ${ }^{17}$

The special views of filial obligations are different from consequentialist explanations because they identify intrinsic features with reference to the process of parent-child interaction. These features may include ideas of indebtedness, gratitude, friendship, or some "special goods" which are shared between agents and their parents. According to these views, adult children have deontic reasons to take care of their parents. Some of these non-consequentialist theories may also be called "analogy-based theories" such as debt theory, gratitude theory, and friendship theory-because they tend to explain the grounds of filial obligations with reference to an analogy of some relevantly similar obligations (Wee 2014, pp. 83-97; Keller 2006, p. 264).

First of all, proponents of debt theory state that adult children should take care of their parents because this is what they owe them (Sommers 1986, pp. 439-456; Post 1989, pp. 315-325; Wee 2014, pp. 83-97; Confucius 1979, 17.21; Ivanhoe 2007, p. 300). According to this view, the moral relation between parents and adult children is comparable to that of the relation between creditors and debtors. Secondly, gratitude theory argues that adult children owe their parents a debt of gratitude since they have received great goods from them (Berger 1975, pp. 298-309; Jecker 1989, pp. 73-80; Ivanhoe 2007; Wicclair 1990, pp. 163-189). The third is friendship theory; its proponents state that the source of moral concern

\footnotetext{
17 There have been different ways to categorize the various explanations of filial obligations. Collingridge and Miller (1997) distinguish between "reciprocity model," "needs-based model," "friendship model," and "conventionalist model." Li (1997) puts forward "English's Friendship Model", "Belliotti's Contribution to Self Principle," "Narveson's Prudent Investor Thesis," "Sommers' Conventional Expectation Thesis," "Blustein's Gratitude Theory," and "The Confucian Alternative". Keller (2006) suggests "the debt theory," "the gratitude theory," "the friendship theory," and his own "special goods theory." Most recently, Schinkel (2012) discusses "past parental sacrifices model," "the special relationship model," and "the conventionalist model." Since Keller's categories have a wider circulation than those of others, I will follow Keller in my discussion.
} 
between parents and adult children lies in the quality of the two parties' existing friendly relations-not in what one party has done to the other in the past (English 1992, pp. 147-154; Blustein 1982; Dixon 1995, pp. 77-87). Finally, there is special goods theory, which argues that the gatherings and interactions between adult children and their parents may give rise to special goods which participants cannot obtain from anywhere else. These goods may include having children around oneself on special occasions, the experience of a sense of continuity or transcendence beyond the duration of one's life, etc. (Keller 2006, pp. 264-268).

Given the wide spectrum of these filial theories, why do we add an explanation of filial obligation from consequentialism? My thought is that consequentialism provides explanations of the obligation from a general ethical framework, making it possible for investigators to adopt a macroscopic vision to oversee the various aspects of filial obligations; we may, as a result, analyze the conflict between the demands of filial obligations and those of other aspects of the adult children's lives. By contrast, on their own, the special views of filial obligations tell us very little about the extent of moral demands in the case of long-term caregiving. If an adult child prefers to use his energy and resources to improve his own well-being than to improve that of his aging parents, proponents of either the friendship theory or the gratitude theory may not have much to say regarding the moral acceptability of this action.

Despite the apparent differences between the consequentialist explanations and the special views of filial obligations, there are ways in which the two types of views are compatible with one another. For example, proponents of special goods theory argue that since the goods stemming from parent-child interaction may not be obtained from the activities of other types of human interaction, there is moral reason for adult children to provide the respective goods to their parents. ${ }^{18}$ This view may be objectionable; the mere fact that special goods may be generated from a person's interaction with another will not make it obligatory for this person to perform the actions in question. $^{19}$

The special goods theory, however, can cohere with a broad theory of consequentialism. By showing why acts of long-term caregiving will enhance the lives of participants, special goods theory may flesh out the skeleton of the ruleconsequentialist explanation regarding the notions of internalization costs and the direction of moral education.

\footnotetext{
18 Keller (2006, p. 273; 2007, p. 139) states: "I think that it should at least be clear that when you are uniquely placed to provide someone with an important good, you have a moral reason to do so, at least in some sense and other things being equal."

19 See, for instance, Thomson (1986, pp. 49-51).
}

Fulfillment of filial obligation strengthens the ties between members of different generations in a family. They offer people a protection "against some of the worst possibilities that life might present." (Hooker 2000, p. 141; Keller 2006 , p. 267) When we say that adult children have reason to bear great sacrifice in order to maximize the good, we can specify this goodness as "a sense of continuity and transcendence" for the people in the filial relationship in question, which extends into society at large (Keller 2006). ${ }^{20}$ From this perspective, the care people give to their parents and grandparents may not merely involve sacrifices; rather, the habitual practices of caring for the old people may enrich people's lives, and provide society with a unique cultural dimension. Here, if we are to talk about promoting a different culture, and inculcating a new character in people, we will have to consider the calculus of costs and benefits from a different viewpoint as well (Sin 2012).

This understanding of filial obligation can go along with some interpretation of gratitude theory, too. On its own, gratitude theory may be criticized because in many ways, the requirement of filial obligation is different from the practice of the expression of gratitude in ordinary lives (Keller 2006: 258-261). But the force of gratitude theory may not be derived from its analogous relation with the ordinary interaction between the persons who express gratitude and those who receive it. Gratitude theory may appeal because it is virtuous for people to learn to be grateful towards their parents. The children who have acquired this trait of character are more ready to participate and grow in a community where there are close filial relations. $^{21}$ Proponents of rule-consequentialism can support this view, because it will be easier to teach children such an understanding of filial obligations than to teach them the requirement to repay what one owes to others on impartial moral grounds. Children may learn about a filial moral code from traditional stories and narratives with regards to worthy varieties of filial relations (e.g., Blum 1993: 50; MacIntyre 1981: 216), and society as a whole will be benefited as they pass the stories on to their future generations in similar ways.

In conclusion, I have shown how we may explain the demands of filial obligations from the perspectives of act and rule consequentialism. Despite the commonplace view that filial obligations fall under the scope of imperfect duties, I have identified factors in relation to the determination of filial demands from a rule-consequentialist

\footnotetext{
${ }^{20}$ See also the Analects, 1:9 "Zeng Zi said, 'Conduct the funeral of your parents with meticulous care and let not sacrifices to your remote ancestors be forgotten, and the virtue of the common people will incline towards fullness"" (Confucius 1979).

${ }^{21}$ See also Welch's (2012) discussion of the gratitude and the special goods theories.
} 
viewpoint. These factors include the costs of internalization of filial obligations, and the proportions of the young and the old generations in a population pyramid. I believe that, all things being equal, in a society with an aging population, we may accept the Extreme View of filial obligation. Of course, since the Extreme View may be a broad category, the actual level of stringency of filial obligation will be dependent upon the intensity of the problem of population aging in society. Furthermore, with this understanding, one may wonder if rule-consequentialism has reduced the special nature of filial obligation to a general moral obligation. Towards the end of the paper, I explained why this may not be the case. In reality, rule-consequentialism may even encourage the special views of filial obligation because it represents ways in which adult children and their parents may obtain special goods from engaging in this relationship.

Acknowledgments I thank Ryo Chonabayashi, Lee Siu-fan, Luke Mulhall, and the anonymous reviewers for their comments and suggestions on earlier drafts of this paper.

\section{References}

Aneshensel, C.S., L.I. Pearlin, and R.H. Schuler. 1993. Stress, role captivity, and the cessation of caregiving. Journal of Health and Social Behavior 34(1): 54-70.

Bentham, J. 1970. An introduction to the principles of morals and legislation. London: Athlone.

Berger, F.R. 1975. Gratitude. Ethics 85(4): 298-309.

Blum, L. 1993. Gilligan and Kohlberg: Implications for moral theory. In An ethic of care. Feminist and interdisciplinary perspectives, ed. M.J. Larrabee, 49-68. New York: Routledge.

Blustein, J. 1982. Parents and children. Oxford: Oxford University Press.

Collingridge, M., and S. Miller. 1997. Filial responsibility and the care of the aged. Journal of Applied Philosophy 14(2): 119-128.

Confucius. 1979. Confucius: The Analects (trans: Lau, D.C.). New York: Penguin Books.

Day, A.M., and P.P. Alston. 1988. Stress in primary caretakers of chronic physically disabled children and adults. Rehabilitation Psychology 33(2): 113-119.

Dixon, N. 1995. The friendship model of filial obligations. Journal of Applied Philosophy 12(1): 77-87.

English, J. 1992. What do grown children owe their parents. In Having children, ed. O. O'Neill, and W. Ruddick, 351-356. New York: Oxford University Press.

Griffin, J. 1996. Value judgement: Improving our ethical beliefs. Oxford: Oxford University Press.

Hooker, B. 1990. Rule-consequentialism. Mind 99(393): 67-77.

Hooker, B. 2000. Ideal code, real world. New York: Oxford University Press.

Hooker, B. 2011. Rule consequentialism. In The Stanford encyclopedia of philosophy, ed. E. N. Zalta. Retrieved from http://plato. stanford.edu/archives/spr2011/entries/consequentialism-rule/.

Ivanhoe, P. J. 2007. Filial Piety as a Virtue. In Working virtue: Virtue ethics and contemporary moral problems, ed. R. Walker, and P.J. Ivanhoe, 297-311. U.S.: Oxford University Press.
Jackson, F. 1991. Decision-theoretic consequentialism and the nearest and dearest objection. Ethics 101(3): 461-482.

Jecker, N.S. 1989. Are filial duties unfounded? American Philosophical Quarterly 26(1): 73-80.

Kagan, S. 1989. Limits of morality. Oxford: Oxford University Press.

Keller, S. 2006. Four theories of filial duty. The Philosophical Quarterly 56(223): 254-274.

Laslett, P., and J.S. Fishkin. 1992. Justice between age groups and generations. New Haven: Yale University Press.

Li, C. 1997. Shifting perspectives: Filial morality revisited. Philosophy East and West 47(2): 211-232.

Lüscher, K., and A. Hoff. 2013. Intergenerational ambivalence: Beyond solidarity and conflict. In Intergenerational relations: European perspectives in family and society, ed. I. Albert, and D. Ferringl, 39-64. Bristol: Policy Press.

MacIntyre, A. 1981. After virtue. London: Duckworth.

Mencius. 1970. Mencius. (trans: Lau, D.C.). London: Penguin Books.

Mulgan, T. 2001. The demands of consequentialism. New York: Oxford University Press.

Post, S.G. 1989. What children owe parents. Thought 64(4): 315-325.

Scanlon, T.M. 1998. What we owe to each other. Cambridge: Harvard University Press.

Schinkel, A. 2012. Filial obligations: A contextual, pluralist model. The Journal of Ethics 16(4): 395-420.

Sidgwick, H. 1907. The methods of ethics, 7th ed. Chicago: University of Chicago Press.

Simmons, A.J. 1979. Moral principles and political obligations. New Jersey: Princeton University Press.

Sin, W. 2012. Internalization and moral demands. Philosophical Studies 157(2): 163-175.

Sin, W. 2013. The demandingness of confucianism in the case of long-term caregiving. Asian Philosophy 23(2): 166-179.

Singer, P. 1972. Famine, affluence, and morality. Philosophy and Public Affairs 1(3): 229-243.

Slote, M. 1979. Obedience and illusions. In Having children, ed. O. O'Neill, and W. Ruddick, 319-326. New York: Oxford University Press.

Sommers, C.H. 1986. Filial morality. The Journal of Philosophy 83(8): 439-456.

Thomson, J. 1986. A defense of abortion. In Applied ethics, ed. P. Singer, 37-56. Oxford: Oxford University Press.

Thompson, J. 2009. Intergenerational justice: Rights and responsibilities in an intergenerational polity. Oxon: Routledge.

Unger, P. 1996. Living high and letting die: Our illusion of innocence. New York: Oxford University Press.

United Nations. 2010. World population prospects, the 2010 revision. Retrieved from http://esa.un.org/wpp/population-pyramids/popu lation-pyramids_absolute.htm.

United Nations Development Programme. 2013. Human development report 2013, The rise of the south: Human progress in a diverse world. New York: United Nations Development Programme.

U.S. Department of Health and Human Services. 2013. United States Administration on Aging. Retrieved from http://www.aoa.gov/.

Wee, C. 2014. Filial obligations: A comparative study. Dao 13(1): 83-97.

Welch, B. 2012. A theory of filial obligation. Social Theory and Practice 38(4): 717-737.

Wicclair, M.R. 1990. Caring for frail elderly parents: Past parental sacrifices and the obligations of adult children. Social Theory and Practice 16(2): 163-189. 